\title{
Beytitepe Kireçtaşı'nın (Bornova Fliş Zonu) Gökdere Alanında (İzmir, Batı Türkiye) Planktonik Foraminifer Biyostratigrafisi ve Mikrofasiyes Özellikleri
}

\author{
Bilal SARI \\ Dokuz Eylül Üniversitesi, Mühendislik Fakültesi, Jeoloji Mühendisliği Bölümü, \\ Tınaztepe Kampüsü, 35160 İzmir. (ORCID: 0000-0002-2389-2772)
}

(Alınıs / Received: 20.10.2017, Kabul / Accepted: 30.01.2018, Online Yayınlanma / Published Online: 15.05.2018)

\begin{abstract}
Anahtar Kelimeler Özet: Batı Anadolu'da (Türkiye), Menderes Masifi ile İzmirAnkara Kenedi arasında yer alan Bornova Fliş Zonu (BFZ)

Planktonik Anatolid-Torid'lerin en batı bölümüne karșıllk gelir. BFZ șiddetli foraminifer, Maastrihtiyen, şekilde deforme olmuş Geç Kretase-Paleosen yaşlı bir matriks ve farklı kökene sahip bloklardan yapılıdır. BFZ'nin matriksi baskın

Üst Kretase, olarak fosil içermeyen fliş türü kayalardan (kumtaşı-şeyl Biyostratigrafi, ardalanması) yapılıdır. Bu kırıntılılar, Bornova-Buca ilçeleri Beytitepe Kireçtaşı, (İzmir) ve çevresinde yersel olarak, planktonik foraminifer içeren Bornova FlişZonu pelajik mikritik kireçtaşı ve kalkerli şeyl mercekleri ve ara düzeyleri (Beytitepe Kireçtaşı) içerir. Buca İlçesi'nin kuzeybatısında yer alan Gökdere Köyü ve çevresini içine alan çalışma alanında yüzeyleyen Beytitepe Kireçtaşı'na odaklanan bu çalışma ile istifin planktonik foraminifer biyostratigrafisi ve mikrofasiyes özellikleri ilk kez tanımlanmıștır. Gökdere alanında pelajik, laminalı mikritik kireçtaşı istifi 360 metreye ulaşır. İstif boyunca planktonik foraminifer topluluklarında Abathomphalus mayaroensis, Contusotruncana contusa, Globotruncanita conica ve Racemiguembelina fructicosa gibi türlerinin bulunması, bu kayaların tümüyle geç Maastrihtiyen yaşlı olduğunu gösterir. Bu veri, pelajik kireçtaşlarının altında ve üstünde yer alan fliş türü tortulların da geç Maastrihtiyen yaşlı olduğuna işaret eder. İstifin en üst bölümlerinde, topluluklarda Globotruncana linneiana'nın varlığı, bu istiflerin yaşının en geç Maastrihtiyen'e kadar uzanmadığını gösterir.
\end{abstract}

\section{Planktonic Foraminiferal Biostratigraphy and Microfacies Characteristics of the Beytitepe Limestone (Bornova Flysch Zone) in the Gökdere Area (İzmir, Western Turkey)}

\begin{tabular}{ll}
\hline Keywords & Abstract: The Bornova Flysch Zone (BFZ) located between the \\
& Menderes Massif and the İzmir-Ankara Suture in western Anatolia \\
Planktonic & corresponds to the westernmost part of the Anatolide-Taurides. \\
foraminifera, & The BFZ comprises intensely-sheared Upper Cretaceous- \\
Maastrichtian, & Paleocene matrix and blocks of various origin. The matrix of the
\end{tabular}


B.SARI / Beytitepe Kireçtaşı'nın (Bornova Fliş Zonu) Gökdere Alanında (İzmir, Batı Türkiye) Planktonik Foraminifer Biyostratigrafisi ve Litostratigrafisi

Upper BFZ comprises mainly of unfossiliferous flysch-type rocks Cretaceous, (alternation of sandstones and shales). These clastics locally Biostratigraphy, include planktonic foraminifera-bearing pelagic micritic limestone Beytitepe Limestone, and calcareous shale lenses and interbeds (Beytitepe Limestone) between Bornova-Buca and surroundings. This study focuses on Bornova Flysch the Beytitepe Limestone cropping out in Gökdere village and Zone surroundings (NE of Buca) and deals with the planktonic foraminiferal biostratigraphy and microfacies characteristics of the succession. Thickness of the pelagic laminated micritic limestone succession reaches up to $360 \mathrm{~m}$ in the Gökdere area. Occurrences of Abathomphalus mayaroensis, Contusotruncana contusa, Globotruncanita conica and Racemiguembelina fructicosa within the planktonic foraminiferal assemblages through the succession suggest a late Maastrichtian age for the rocks. This data indicate that the age of the flysch-type rocks below and above the limestones is late Maastrichtian as well. Presence of Globotruncana linneiana in assemblages at top of the succession shows that the age of the limestones does not extend into latest Maastrichtian.

bilal.sari@deu.edu.tr

\section{Giriș}

İzmir ve çevresinde yüzeyleyen ve İzmirAnkara Zonu'nun en batı bölümüne karşılık gelen Bornova Fliş Zonu (BFZ), Menderes Masifi ile İzmir-Ankara Kenedi arasında, 50-90 km genişliğinde ve yaklaşık $230 \mathrm{~km}$ uzunluğunda tektonik bir zondur [1,2] (Şekil 1). Anatolid-Torid Bloğu'nun en batı ucunu oluşturan bu zon, Eosen metamorfizmasindan etkilenmemiştir. Şiddetli bir şekilde deforme olmuş bir matriks ve içinde yüzen Mesozoyik yaşlı kireçtaşı blokları, mafik volkanit, radyolarit ve serpantinitlerden oluşan zonun İzmir ve çevresinde yüzeyleyen bölümü 'Bornova Karmaşı̆̆ı' olarak adlandırılmıştır [3]. Boyu 20 km'ye ulaşan platformdan türeme kireçtaşı bloklarının yaşı TriyasGeç Kretase arasında değişir [1,3-10].

BFZ'nin matriksini baskın olarak, fosil içermeyen fliş türü tortullar (kumtaşçamurtaşı ardalanması) oluşturur. Önceki çalıșmalara göre, bu kırıntılılar yersel olarak Kampaniyen-Erken Paleosen (Daniyen) yaşını işaret eden, planktonik foraminiferli, kalkerli şeyl ve mikritik kireçtaşı mercek ve aradüzeyleri içerir $\quad[4,11,12]$. Kumtaşı-çamurtaşı ardalanması ile yanal ve düșey geçișli olarak bulunan kalkerli şeyl ve mikritik kireçtaşları çoğunlukla Bornova ve çevresinde (Kocaçay deresi, Altındağ güneyi, Işıklar Köyü güneyi, Gökdere Köyü vb.) yüzlek verir ve ilk kez [11] tarafından 'Beytitepe Kireçtaşı' olarak adlandırılmıştır. İrili ufaklı mercek ve arakatkılar şeklinde yüzeyleyen (metre boyutundan 200 metreye kadar) bu karbonatlı düzeyler BFZ'nin matriksini yaşlandırabilecek yegane fosil içeren kayalardır. $\mathrm{Bu}$ nedenle havzanın açılma ve kapanma yaşı ve geçirdiği tektonostratigrafik evrim hakkında önemli paleontolojik veriler sunar. $\mathrm{Bu}$ özellikleriyle bazı çalışmalarda incelenmiș olsalar da, bu istiflerde doğrudan planktonik foraminiferlere yönelik ayrıntılı tek çalışma [13] tarafından yapılmıştır. Gökdere, Işıklar ve Kocaçay alanlarında yürüttüğü çalışmasında [13] Beytitepe Kireçtaşı́nın pelajik istiflerinde geç Maastrihtiyen'den en geç Paleosen'e kadar uzanan yaşlar elde etmiş ve her üç alanda yüzeyleyen istiflerin yaşlarının yeni bulgulara göre 
B.SARI / Beytitepe Kireçtaşı́nın (Bornova Fliş Zonu) Gökdere Alanında (İzmir, Batı Türkiye) Planktonik Foraminifer Biyostratigrafisi ve Litostratigrafisi

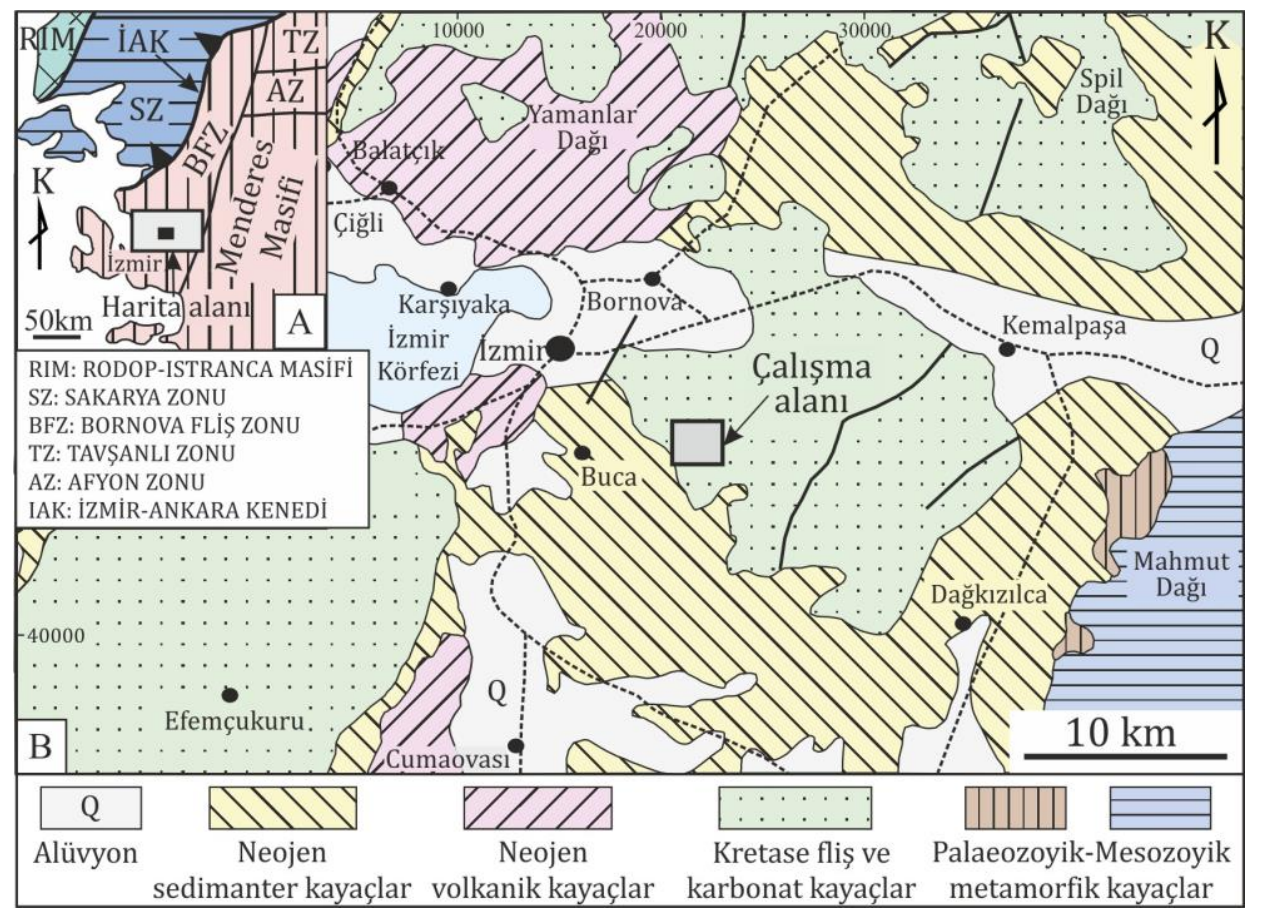

Şekil 1. Çalışma alanının yer bulduru haritası, A) Batı Anadolu'nun ana tektonik kuşakları ([49]'dan basitleştirilerek alınmıştır), Çalışma alanı Torid-Anatolid'lerin en batı ucuna karşılık gelen Bornova Fliş Zonu içinde yer alır. B) İzmir ve çevresinin jeoloji haritası ([50]'den basitleștirilerek alınmıștır).

\begin{tabular}{|c|c|c|c|}
\hline YAŞ & LİTOLOJİ & LİTOLOJİ AÇIKLAMASI & KAYA BİRIMİ \\
\hline $\begin{array}{c}\text { Geç Kretase } \\
\text { (Santoniyen) } \\
\text { en geç Paleosen- } \\
\text { geç Maastrihtiyen } \\
\text { geç Maastrihtiyen }\end{array}$ & 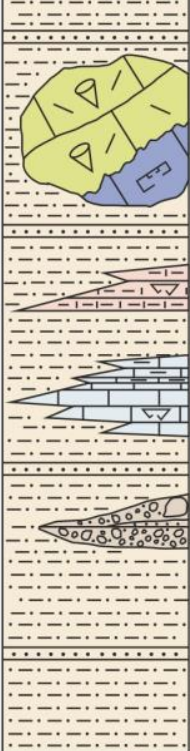 & 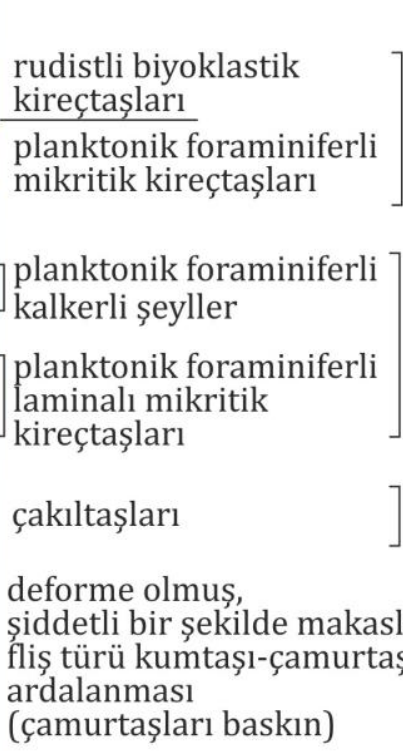 & $\begin{array}{l}\left.\begin{array}{l}\text { Beytitepe } \\
\text { Kireçtaşı }\end{array}\right\} \begin{array}{c}\text { ÇALIŞILAN } \\
\text { DÜZEY }\end{array} \\
\text { Kocaçay Çakıltaşı } \\
\text { lanmış, } \\
\begin{array}{c}\text { Şı } \\
\text { makaslanmış } \\
\text { fliş }\end{array}\end{array}$ \\
\hline
\end{tabular}

Şekil 2. Bornova Fliş Zonu'nun matriksinin, çalışma alanı ve yakın çevresinde, basitleştirilmiş litostratigrafik kolon kesiti [13]. 
B.SARI / Beytitepe Kireçtaşı'nın (Bornova Fliş Zonu) Gökdere Alanında (İzmir, Batı Türkiye) Planktonik Foraminifer Biyostratigrafisi ve Litostratigrafisi

revize edilmesi gerektiğini öne ve tane planktonik foraminifer sürmüştür. Pelajik istifin en kalın olduğu tanımlamaları ile oluşturulan Gökdere istifinin planktonik biyozonasyona çok yakın çözünürlük foraminiferleri ve litostratigrafik sunmaktadır [16]. İnce kesitten özellikleri ise bugüne değin planktonik foraminifer tanımlamalarında çalışılmamıştır. $\mathrm{Bu}$ çalışma, Gökdere kullanılan, kavkının boyut ve şekli, spiral istifinde yüzlekler veren Beytitepe ve ombilikal tarafların içbükeylik ve Kireçtaşı'nın planktonik foraminifer dışbükeylik dereceleri, kavkı duvarının biyostratigrafisini ve litostratigrafik kalınlığı, locaların boyut, sayı ve dizilim özelliklerini konu edinir.

\section{Materyal ve Metot}

Bu çalışma stratigrafik kesit ölçümüne ve kesitler boyunca sistematik örnek derlemeye dayandırılmıştır. Örnekleme sıklığı kesitin farklı düzeylerinde değişmekle birlikte, ortalama olarak her 40-100 cm'de bir örnek alınmış, bazı kesimlerde örnekleme aralığı 30, 20 hatta $10 \mathrm{~cm}$ 'ye düşürülmüștür. Laminalı mikritik kireçtaşı ve karbonat içeriği fazla olan dayanımlı kalkerli şeyler gibi sert litolojilerden planktonik foraminifer ve fasiyes tanımlama amacıyla ince kesit amaçlı örnekler derlenmiş, az karbonatlı kalkerli şeylerden ise yıkama amaçlı örnekler derlenmiștir. Gökdere istifi boyunca ince kesit amaçlı 152 adet, yıkama örneği amaçlı 35 adet örnek derlenmiștir. Yıkama örneklerine standart hidrojen peroksit yöntemi uygulanmış, ancak kayaların az karbonatlı bölümlerinin dahi iyi tutturulmuş olması ve kayaların çoğunlukla aşırı makaslanmış olması nedeniyle, sağlıklı tanımlama yapilabilecek temiz tane foraminifer elde edilememiştir. Standart hidrojen peroksit yönteminden istenen sonucun elde edilememesinin ardından, daha sert kayalardan tane örnek elde etmekte kullanılan asetik asit yöntemi uygulanmış [14], bu yöntemle de iyi sonuçlar alınamamıştır. İnce kesitlerde, aksiyal kesit ya da aksiyal kesite çok yakın kesite sahip planktonik foraminiferler seçilmiş ve tanımlanmıştır. İnce kesitten planktonik foraminifer tanımlama yöntemi oldukça eski bir geçmișe sahiptir (Literatür için $[13,15]$ 'e bakınız) şekli, omuz ve diken gibi süs elemanları ve karenlerin sayısı ve konumu gibi önemli özellikler aksiyal ve aksiyale yakın kesitlerde kolaylıkla tanınabilmektedir $\quad[16,17]$ İnce kesitlerden Geç Kretase planktonik foraminifer tanımlamaları yapılırken [13,15-26]'dan yararlanılmıștır. Planktonik foraminiferlerin yașlarını yorumlarken, son yıllarda yapılan birçok önemli çalışmada olduğu gibi [2124,27,28] tarafından önerilen zaman çizelgesine göre düzenlenmiş dağllım ve biyozonasyondan yararlanılmıștır. Mikrofasiyes tanımlamalarında [29] tarafından değiştirilmiş [30]'un doku ağırlıklı kireçtaşı sınıflaması kullanılmıştır.

\section{3. Çalıșma Alanının Yeri}

Çalışma alanı Türkiye'nin batısında yer alan İzmir İli'ne bağlı Buca İlçesi'nin doğusunda yer alır (Şekil 1,2,3). Çalışmalar Buca İlçesi'nin yaklaşık 5 km KD'sinde yer alan Gökdere Köyü ve yakın çevresinde gerçekleștirilmiștir (Şekil 2, 3). İzmir L18-a2 ve İzmir L18-b1 paftaları içinde yer alan çalışma alanı güneybatıda Gökdere Köyü'nü içine alır ve kuzeyde Bornovalı Tepe'ye kadar uzanır (Şekil 2, 3).

\section{4. Önceki Çalışmalar}

$\mathrm{Bu}$ güne değin, BFZ'nin yaşını, stratigrafik ve tektonik özelliklerini ve geçirdiği tektono-stratigrafik evrimi ortaya koymaya yönelik önemli çalışmalar yapılmıştır. Zonun karmaşık jeolojisi nedeniyle, bölgede yaplan ilk çalışmalarda, kireçtaşı kütlelerinin ve flişin yaşı ve stratigrafik ilişkileri 
B.SARI / Beytitepe Kireçtaşı'nın (Bornova Fliş Zonu) Gökdere Alanında (İzmir, Batı Türkiye) Planktonik Foraminifer Biyostratigrafisi ve Litostratigrafisi

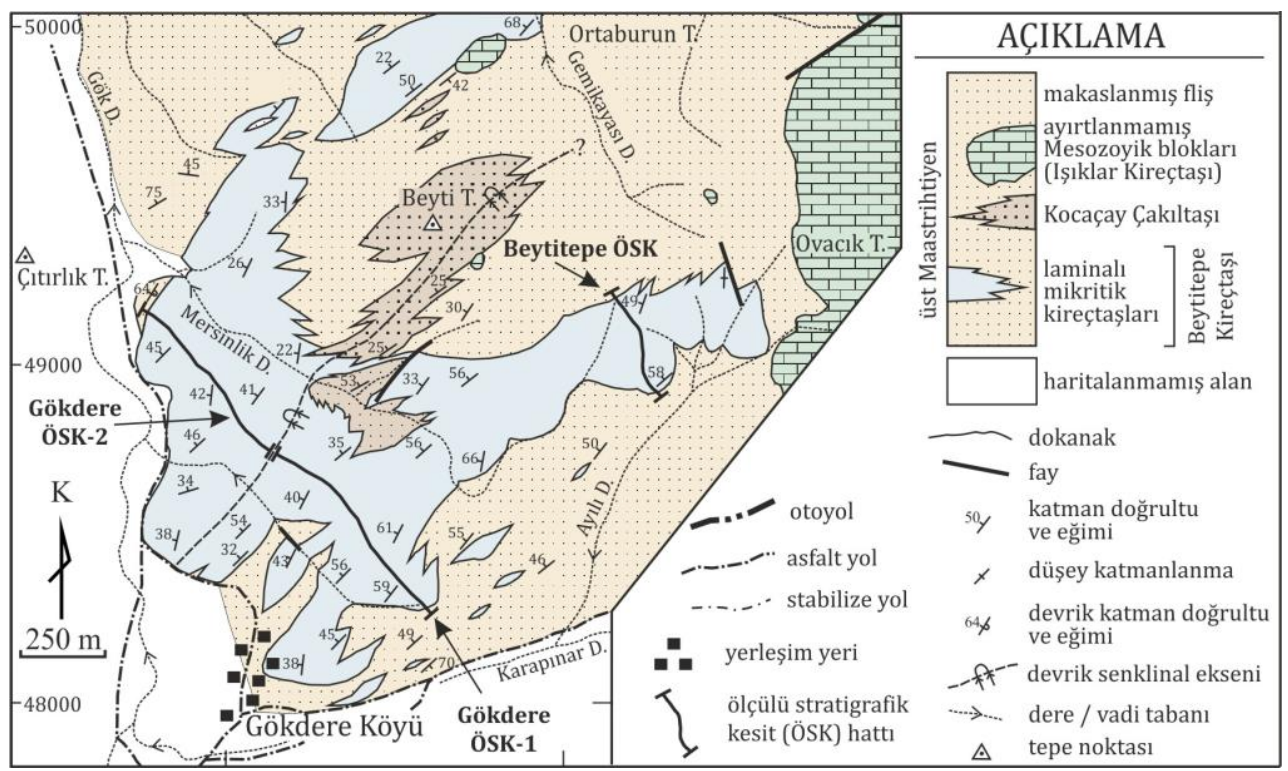

Şekil 3. Gökdere Köyü ve çevresinin jeoloji haritası ([13]'den değiştirilerek alınmıştır).

konusunda birbirinden farklı sonuçlar elde edilmiștir [11,12,31-40]. İlerleyen yıllarda BFZ'nin bloklarının ve matriksinin yaşı ve stratigrafik ve tektonik ilişkileri hakkında daha ayrıntılı veriler elde edilmiştir [1-7,10,11,41-45]. İzmir ve çevresinde doğrudan Beytitepe Kireçtaşı'nın yaşı hakkında veriler içeren çalışmalar olmakla birlikte, ilk sağlıklı veriler [3] tarafından elde edilmiş, planktonik foraminiferlere dayalı ayrıntılı tek çalışma ise [13] tarafından gerçekleştirilmiştir.

\section{Beytitepe Kireçtaşı'nın Stratigrafisi}

Önceki çalışmalarda Bornova Karmaşı̆̆ı olarak da adlandırılan BFZ Bornova ve Buca çevrelerinde karbonat arakatkılar içeren fliş türü kırıntılı bir matriks ve bu matriks içinde yüzen çeşitli boyda kireçtaşı bloklarından oluşur (Şekil 4). Çalışma alanında matriksi, [4] tarafından makaslanmış fliş olarak adlandırılan kumtaşı-şeyl ardalanması, Kocaçay Çakıltaşı olarak adlandırılan çakıltaşları ve [11] tarafından Beytitepe Kireçtaşı olarak adlandırılan laminalı mikritik kireçtaşları ve karbonat içeriği değişen kalkerli şeyler oluşturur (Şekil 2). Matriks baskın olarak makaslanmıș flişten yapılıdır. Laminalı mikritik kireçtaşları ve kalkerli şeyller fliş içinde kalınlıkları değişen mercekler şeklinde yer alırlar ve yanal ve düşey yönde flişi oluşturan kumtaşı-şeyl ardalanması ile giriklikler sunarlar. Bu nedenle yanal yönde kısa mesafelerde kalınlık değişimi gösterirler. Çalışma alanında laminalı mikritik kireçtaşlarının kumtaşıçamurtaşı ardalanması içinde incelip kalınlaşan bir mercek şeklinde yer aldığ ortaya çıkmıştır (Şekil 3). Çalışma alanının güney bölümünde bu merceğin Ovacık Tepe'den Gökdere Köyü'ne doğru

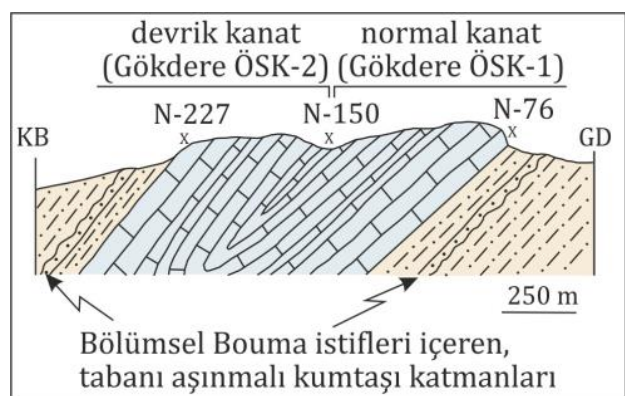

Şekil 4. Gökdere ÖSK-1 ve Gökdere ÖSK2'nin ölçüldüğü hat boyunca jeolojik yapıyı gösteren basitleștirilmiș enine kesit [13]. 
kuzeybatıya eğimli bir düzey şeklinde uzandığı görülür. [11]'in de belirttiği gibi Gökdere Köyü'nün hemen kuzeyinde bu düzey, devrik bir senklinal oluşturur ve irili ufaklı merceklere dönüşerek çalışma alanının kuzeyinde yer alan Bornovalı Tepe'ye doğru incelerek uzanır (Şekil 3). $\mathrm{Bu}$ jeolojik yapı göz önünde bulundurularak, Gökdere Köyü'nün kuzeyinde istifin en kalın olduğu ve en iyi gözlendiği hattan ölçülü stratigrafi kesiti alınmıştır. Güneybatıda fliş ile başlayan istif, katmanların eğim açllarında belirgin bir değişim olmadan kuzeybatıya doğru laminalı mikritik kireçtaşları ile devam eder ve en kuzeybatıda yine flişle son bulur (Şekil 3,4). Jeolojik haritalama çalışmaları sonucunda bu alanda istifin devrik olduğunun anlaşılmasının ardından, bu hat boyunca tüm laminalı mikritik kireçtaşı istifini kesen GD-KB doğrultulu bir ölçülü stratigrafi kesiti alınmıştır. Kesit hattı boyunca 740 metre kalınlığında bir kalınlık kesilmiş, istifin devrik olması nedeniyle güneydoğuda yer alan 370 metre kalınlığındaki ilk bölüm Gökdere ÖSK-1, kuzeybatıda yer alan 370 metre kalınlığındaki ikinci bölüm ise Gökdere ÖSK-2 şeklinde adlandırılmıştır. İstifin devrik olduğu dikkate alındığında bu iki kesitin birbirinin eşleniği olduğu ve bu alanda laminalı mikritik kireçtaşlarının 360 metrelik kalınlığa ulaştığı görülür (Şekil 4). Beytitepe ÖSK'de kalınlığın 220 metre olduğu düşünüldüğünde güneybatıya doğru kısa bir mesafede (yaklaşık $11 \mathrm{~km}$ ) laminalı mikritik kireçtaşlarının kalınlığının 140 metre arttığı görülür. İstifin normal kanadı Gökdere ÖSK-1, devrik kanadı ise Gökdere ÖSK-2 olarak adlandırılmış ve her iki kesit boyunca yapılan gözlemlerden elde edilen veriler aşağıda ayrıntıları ile verilmiştir.

5.1. Gökdere ölçülü stratigrafi kesiti-1 Gökdere ÖSK-1, Gökdere Köyü'nün yaklaşık $250 \mathrm{~m}$ KD'sinden başlayıp KB doğrultusu boyunca ölçülmüştür (Şekil
3,4). Kesit Başlangıç Koordinatı: 0521583/4248281, Kesit Bitiş Koordinatı: 0521150/424875.

Gökdere ÖSK-1'de laminalı mikritik kireçtaşları fliş türü tortulları dereceli bir dokanakla üzerler (Şekil 3,4,5). Laminalı mikritik kireçtaşlarının 360 metrelik bir istif sunduğu Gökdere ÖSK-1 tabanda kumtaşı-şeyl ardalanması ile başlar. Bölümsel Bouma istifleri içeren kumtaşı katmaları (Şekil 5A) kaba kumtaşı ile bașlayıp üste doğru ince kumtaşına ve en üstte dereceli olarak laminalı çamurtaşlarına geçer. Katmanların konumları istifin bu kesimde normal olduğunu gösterir. Fliş türü tortullar üste doğru laminalı mikritik kireçtaşlarına geçer. $\mathrm{Bu}$ kesimde kumtaşlarının ve laminalı mikritik kireçtaşlarının doğrultu-eğim değerleri (K56D/64KB) birbirine yakındır (Şekil 3).

İstifin karbonatça baskın bölümü tabanda 3,5 metre kalınlığındaki laminalı killi kireçtaşları ile başlar ve üste doğru gri-boz renkli laminalı mikritik kireçtaşlarına geçer, bu kesimler alttaki düzeylere oranla daha bol planktonik foraminifer içerir. İstif boyunca baskın litoloji laminalı mikritik kireçtaşları olmakla birlikte, kalınlığı değişen birçok laminalı killi kireçtaşı düzeyi gözlenir (Şekil 5). Laminalı mikritik kireçtaşları bazı kesimlerde geçirdikleri deformasyonun izlerini açık olarak gösterirler (Şekil 5B). Bu deformasyon kireçtaşlarının tüm istif boyunca farklı yoğunluklarda olmak üzere yapraklanma kazanmasına neden olmuştur. İstifin bazı düzeylerinde yapraklanmanın oldukça ince olduğu görülür (Şekil 5C). Yapraklanma düzlemlerinin ilksel laminalanmayı kestiği, arazide yüzleklerde ve ince kesitlerde seyrek de olsa gözlenmektedir. Laminalı mikritik kireçtaşları ve killi mikritik kireçtaşlarının rengi istif boyunca baskın olarak gridir. Grinin yanında, açık gri, 

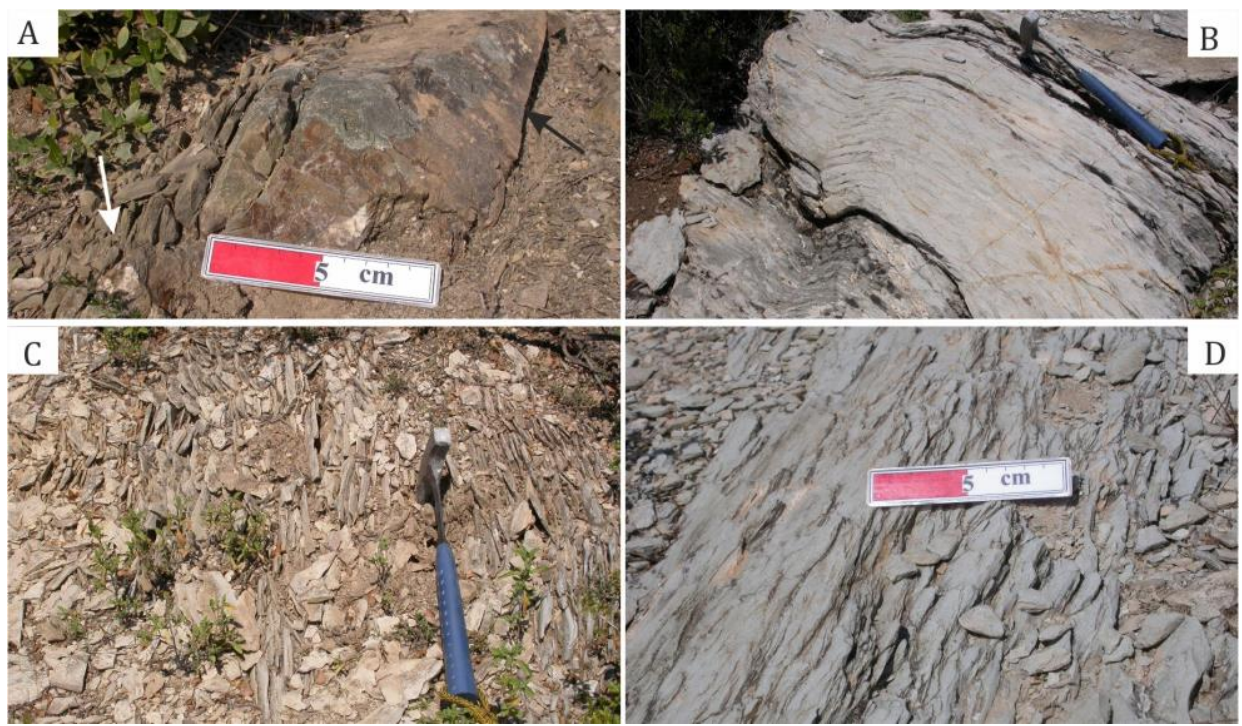

Şekil 5. Gökdere ÖSK-1 boyunca çeșitli düzeylere ait kaya türleri, A) İstifin tabanında gözlenen ve bölümsel Bouma istifleri içeren kumtaşları. Koord:0521583/4248281, B) Kıvrımlar içeren laminalı mikritik kireçtaşlarının genel görünümü. Koord:0521549/4248453. İstifin 174. metresi, C) İnce laminalı mikritik kireçtaşlarının genel görünümü. Koord:0521460/4248586. İstifin 290. metresi, D) Uçuk yeşilimsi gri renkli laminalı killi kireçtașlarının genel görünümü. Koord:0521455/4248638. İstifin 320. metresi.

pembemsi gri, uçuk pembe ve uçuk yeşilimsi gri gibi renklerin ardalanması şeklinde de renk sunarlar (Şekil 5B-D). Kil içeriğinin daha fazla olduğu düzeyler mikritik düzeylere oranla daha az planktonik foraminifer içerirler. İstif boyunca iki farklı düzeyde ekinid kavkı parçalarına rastlanmıştır. İstifin 162 . ve 215. metrelerinde gözlenen ekinidler kayaçla bütünleşmişlerdir ve özellikle yapraklanma düzlemleri kavkıları da kestiğinden kayaç içinden çıkarılamazlar. İstif boyunca örneklerin ince kesitleri incelendiğinde baskın mikrofasiyesin planktonik foraminiferli vaketașı olduğu görülür (Şekil 6A,B). Planktonik foraminiferlerin daha seyrek olduğu bölümler ise planktonik foraminiferli karbonat çamurtaşı mikrofasiyesi ile temsil edilir. Bazı düzeylerde her iki mikrofasiyesi tek bir örnekte görmek mümkündür. İstif boyunca ince kesitlerde çoğunlukla basınç çözünmeleri yaygındır, bu kesimlerde planktonik foraminiferler de basınç çözünmesi düzlemleri tarafından kesilirler (Șekil $6 C, D)$. Bazı düzeyler ise bu tektonik etkiden korunmuşlardır ve basınç çözünmesi düzlemleri içermezler (Şekil $6 \mathrm{~A}, \mathrm{~B})$.

\subsection{Gökdere ölçülü stratigrafi kesiti-2}

Gökdere ÖSK-2, Gökdere Köyü'nün yaklaşık $1 \mathrm{~km}$ kuzeybatısında Gök Dere'nin dere yatağına yakın bir noktadan başlar ve GD doğrultusu boyunca ölçülmüștür (Şekil 3,4). Kesit Başlangıç Koordinatı: 0520803/4249093, Kesit Bitiş Koordinatı: 0521150/424875.

Gökdere ÖSK-2 tabanda fliş ile başlar. Flişi oluş̧uran kumtaşı katmanları incelendiğinde, bu kesimde de, Gökdere ÖSK-1 de olduğu gibi kumtaşı katmanlarının bölümsel Bouma istifleri içerdiği görülür. Oturma yapıları içeren katman yüzeylerinin üstte olması ve katmanların alta doğru dereceli olarak laminalı çamurtaşlarına geçiş sunmaları 

Foraminifer Biyostratigrafisi ve Litostratigrafisi

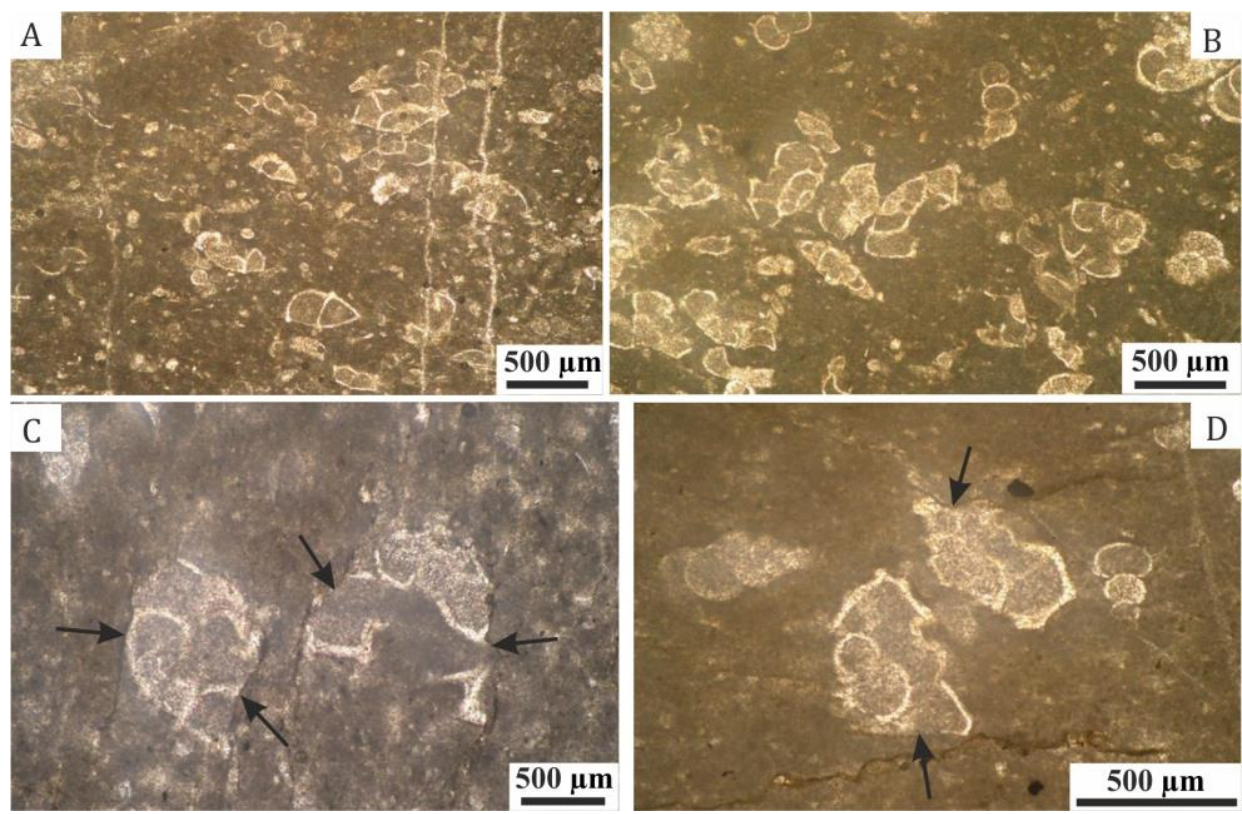

Şekil 6. Gökdere ÖSK-1 boyunca laminalı mikritik kireçtaşlarına ait çeșitli litofasiyesler, A, B) Basınç çözünmesinin etkisinden korunmuş bol planktonik foraminifer içeren düzeylerin mikroskop görüntüsü. Sırasıyla örnek no: N-111 ve N-120. C,D) Basınç çözünmesi (siyah oklar) nedeniyle kesilmiş planktonik foraminiferler. Sırasıyla örnek no: N-84 ve N-123.

(Șekil 7A,B) istifin bu bölümde devrik olduğunun verileridir. Fliși üzerleyen laminalı mikritik kireçtaşlarının fasiyes özellikleri, kesit hattının 50 metre batısındaki yol yarmasında açık olarak gözlenir (Şekil 7C-F). İstifin bu düzeylerinde kayaçların birbirini kesen yapraklanma düzlemleri içerdiği açık olarak gözlenir. Laminalı mikritik kireçtaşlarının baskın olduğu bu düzeyler bol planktonik foraminifer içerirler (Şekil 7E). Bu düzeylerde ayrıca seyrek de olsa ekinid parçaları da gözlenir (Şekil 7F). Bu düzeyin dışında, istif boyunca iki farklı ekinidli düzey daha gözlenir. Bu düzeyler istifin 115125. metreleri arasina ve 235. metresine kaşılık gelir ve oldukça bol miktarda ekinid kavkı parçası içerir. Gökdere ÖSK1'de olduğu gibi Gökdere ÖSK-2'de de ekinidler kayaçla bütünleşmişlerdir ve kayaç içinden çıarılamazlar. İstif boyunca örneklerin ince kesitleri incelendiğinde, istifin Gökdere ÖSK-1'nin eşleniği olması nedeniyle benzer mikrofasiyesler gözlenmektedir ve baskın mikrofasiyesin planktonik foraminiferli vaketaşı olduğu görülür. Planktonik foraminiferlerin daha seyrek olduğu bölümler ise planktonik foraminiferli karbonat çamurtaşı mikrofasiyesi ile temsil edilir (Șekil 8AC). İstif boyunca yine ince kesitlerde çoğunlukla basınç çözünmeleri yaygındır, bu kesimlerde planktonik foraminiferler de basınç çözünmesi düzlemleri tarafından kesilirler (Şekil 8A-D). Arazi çalışmaları sırasında görülmediği halde bazı düzeylerin ince kesitlerinde ekinid kavkı parçaları gözlenmektedir (Şekil 8D).

\section{6. İstifin Planktonik Foraminifer Biyostratigrafisi}

Her iki ÖSK'de bol planktonik foraminifer içeren düzeyler olsa da seyrek ve ortaç planktonik foraminiferli düzeyler daha baskındır (Şekil 9,10). Bazı düzeylerden alınan örneklerde ise hemen hemen hiç planktonik foraminifer gözlenmemekte- 


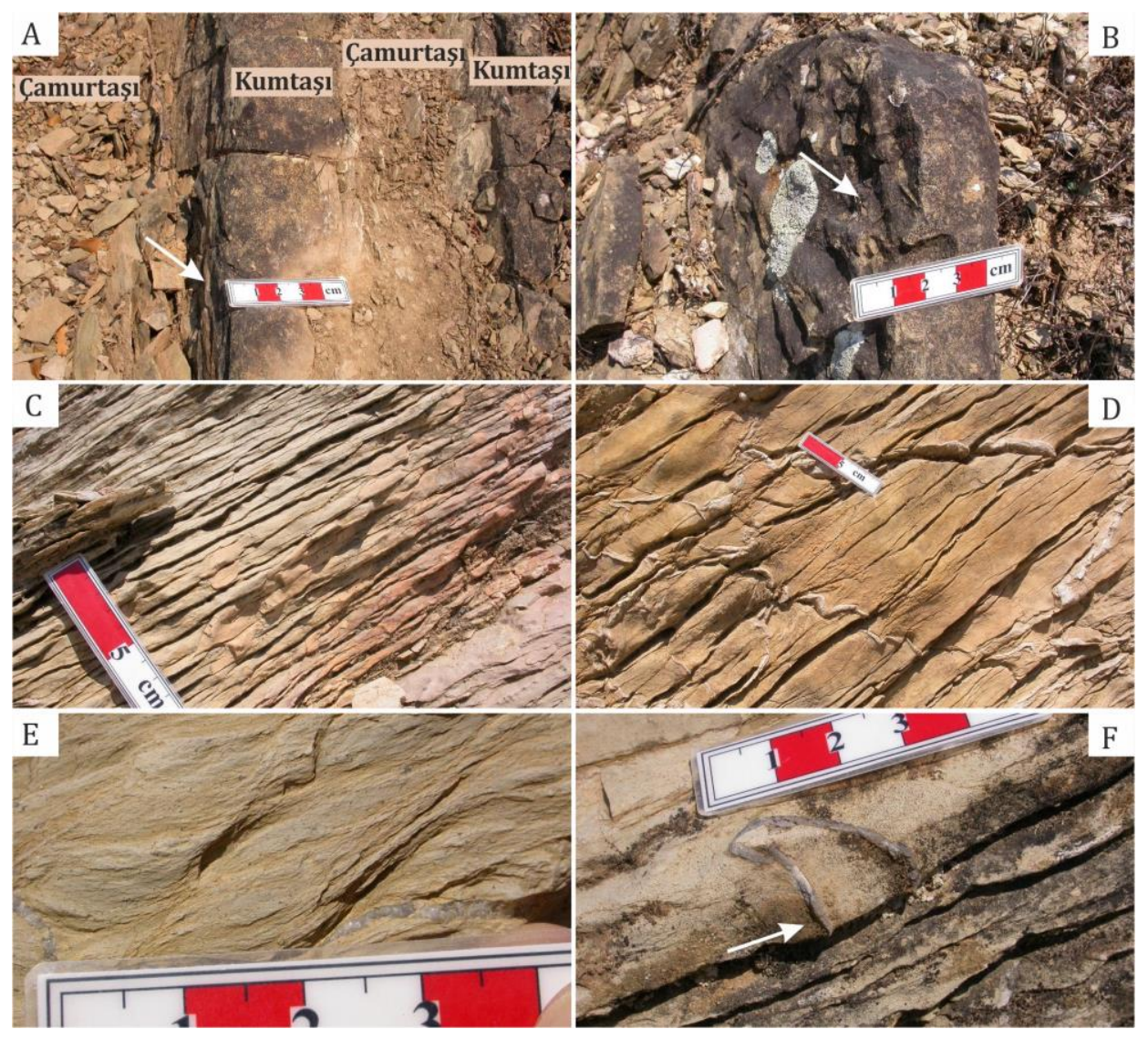

Şekil 7. Gökdere ÖSK-2 boyunca çeșitli düzeylere ait kaya türleri, A,B) İstifin tabanında yer alan flişin yakından görünümü. Bölümsel Bouma istifleri içeren kumtaşı katmanları devrik konumdadır. Koord:0520803/4249175, C,D). Laminalı mikritik kireçtaşlarının genel görünümü. Koord:0520815/4248786. İstifin 22. metresi, E) laminalı mikritik kireçtaşlarının yakından görünümü. Planktonik foraminiferler gri noktalar şeklinde çıplak gözle seçilebilir, F) Laminalı mikritik kireçtaşlarında gözlenen ekinid kavkı parçası (beyaz ok). Koord: 0520815/4248786. İstifin 20. metresi.

dir. Gökdere ÖSK-1'de istifin 200 metre kalınlığındaki alt bölümünde planktonik foraminiferler bağll olarak daha boldur. Üst bölümlerde ise planktonik foraminiferler belirgin bir şekilde seyrekleşir (Şekil 9). Gökdere ÖSK-2'de de bu durum, daha az belirgin olmakla birlikte gözlenebilir (Șekil 10). İstifin yoğun basınç çözünmesi düzlemleri içermesi foraminifer tanımlamalarını çoğu durumda zorlaştıran bir etkendir. Her iki ÖSK'nin de aynı stratigrafik düzeyi kesmesi nedeniyle ÖSK'ler boyunca tanımlanan planktonik foraminifer topluluklarının benzer olduğu görülür (Şekil 9,10). Gökdere ÖSK-1 ve Gökdere ÖSK-2'de $A$. mayaroensis, C. contusa, C. fornicata, $C$. patelliformis, $C$. cf. plicata, C. plummerae, C. walfischensis, Ga. cf. gansseri, G. arca, $G$. arca-orientalis, G. bulloides, G. dupeublei, G. esnehensis, G. falsostuarti, G. hilli, G. linneiana, G. mariei, $G$. orientalis, $G$. ventricosa, Gl. havanensis, Gl. petaloidea, Gt. angulata, Gt. conica, Gt. elevata, Gt. insignis, Gt. pettersi, Gt. stuarti, Gt. stuartiformis, R. fructicosa, $R a$. 

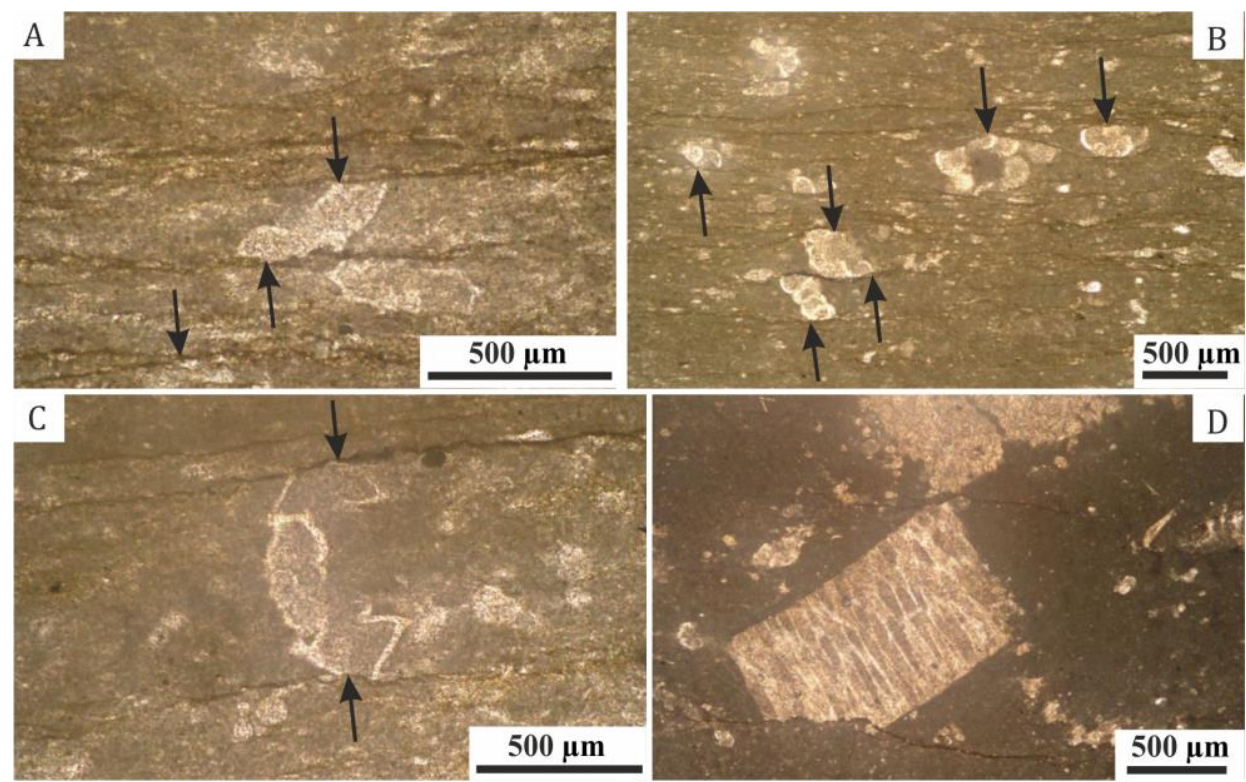

Şekil 8. Gökdere ÖSK-2 boyunca laminalı mikritik kireçtaşlarına ait çeşitli litofasiyesler, $A, B, C)$ Seyrek planktonik foraminiferli karbonat çamurtaşı mikrofasiyesleri. Planktonik foraminiferler basınç çözünmesi (siyah oklar) nedeniyle kesilmiş. Sırasıyla örnek no: N-154, N-168 ve N-217, D) Ekinid kavkı parçalı yüzertaş mikrofasiyesi. Örnek no: N-214.

subspinosa, Ru. milamensis, Ru. pennyi, Ru. rugosa, ve Gublerina sp.'den olușan planktonik foraminifer toplulukları gözlenmektedir (Şekil 9,10). Ayrıca, topluluğa çeşitli düzeylerde tanımlanamayan iki sıralı ve çok sıralı heterohelisidler eşlik eder. Bu topluluklar içinde seyrek de olsa, her iki ÖSK'de de istifin en altından itibaren üst bölümlere kadar $A$. mayaroensis'in varlı̆̆ı, Beytitepe ÖSK'de olduğu gibi [13] Gökdere ÖSK'lerinde kesilen laminalı mikritik kireçtaşlarının tümüyle geç Maastrihtiyen yaşını işaret eden $A$. mayaroensis biyozonu içinde olduğunu kanitlar (Șekil 12) [13,15-20,22$26,28,46,47]$. Topluluk içinde gözlenen $C$. contusa ve $R$. fructicosa türleri de geç Maastrihtiyen'in alt bölümlerine karşıllık gelen $C$. contusa- $R$. fructicosa biyozonunu işaret eden diğer geç Maastrihtiyen formlarıdırlar (Şekil

$[20,22,24,47,48]$. Gt. conica da yaygin olarak geç Maastrihtiyen'de gözlenen bir taksondur. Diğer yandan, G. linneiana'nın her iki ÖSK'de de istifin en üst bölümle- rinde gözlenmesi (N-148 ve N-149 nolu örnekler) istifin yaşının en geç Maastrihtiyen'e kadar uzanmadığını gösterir (Şekil 9,10,12). Planktonik foraminiferlerin örneklere göre dağılımı için Şekil 9 ve $10^{\prime}$ a, tanımlanan formların mikroskop görüntüleri için Şekil 13'e bakınız.

Gökdere istiflerinde gözlenen planktonik foraminifer toplulukları, klasik pelajik Tetis istiflerinde gözlenen topluluklarla benzer olmakla birlikte [24,47] bazı taksonların istiflerde bulunması klasik stratigrafik dağllımlara uymamaktadır. Örneğin Gt. elevata Kampaniyen formu olarak bilinir ve Maastrihtiyen yaşlı tortullarda gözlenmez [24,47]. $\mathrm{Bu}$ çalışmada, Gökdere ÖSK-1'de N-99, N104 ve N-110 nolu örneklerde, Gökdere ÖSK-2'de de N-204 nolu örnekte, son turun son locasının iriliği, spiral tarafta merkezde yer alan konik yapısı ve tek karenli loca kenar açılarının dik oluşuyla tipik Gt. elevata özellikleri gösteren formlar tanımlanmıștır (Şekil 13P1, R1). 
B.SARI / Beytitepe Kireçtaşı'nın (Bornova Fliş Zonu) Gökdere Alanında (İzmir, Batı Türkiye) Planktonik Foraminifer Biyostratigrafisi ve Litostratigrafisi

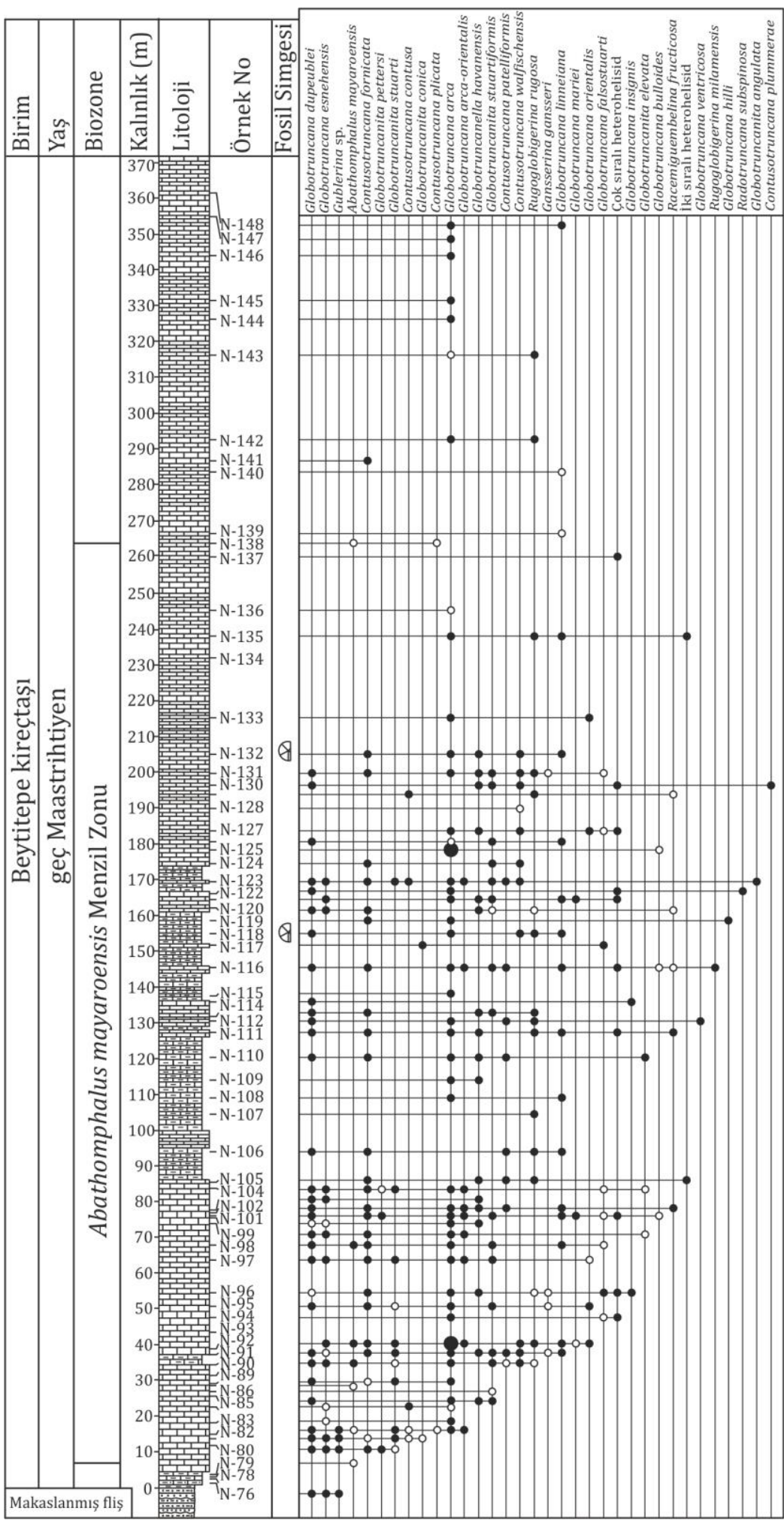

Șekil 9. Gökdere ÖSK-1'de planktonik foraminiferlerin stratigrafik dağılımı. 
B.SARI / Beytitepe Kireçtaşı'nın (Bornova Fliş Zonu) Gökdere Alanında (İzmir, Batı Türkiye) Planktonik Foraminifer Biyostratigrafisi ve Litostratigrafisi

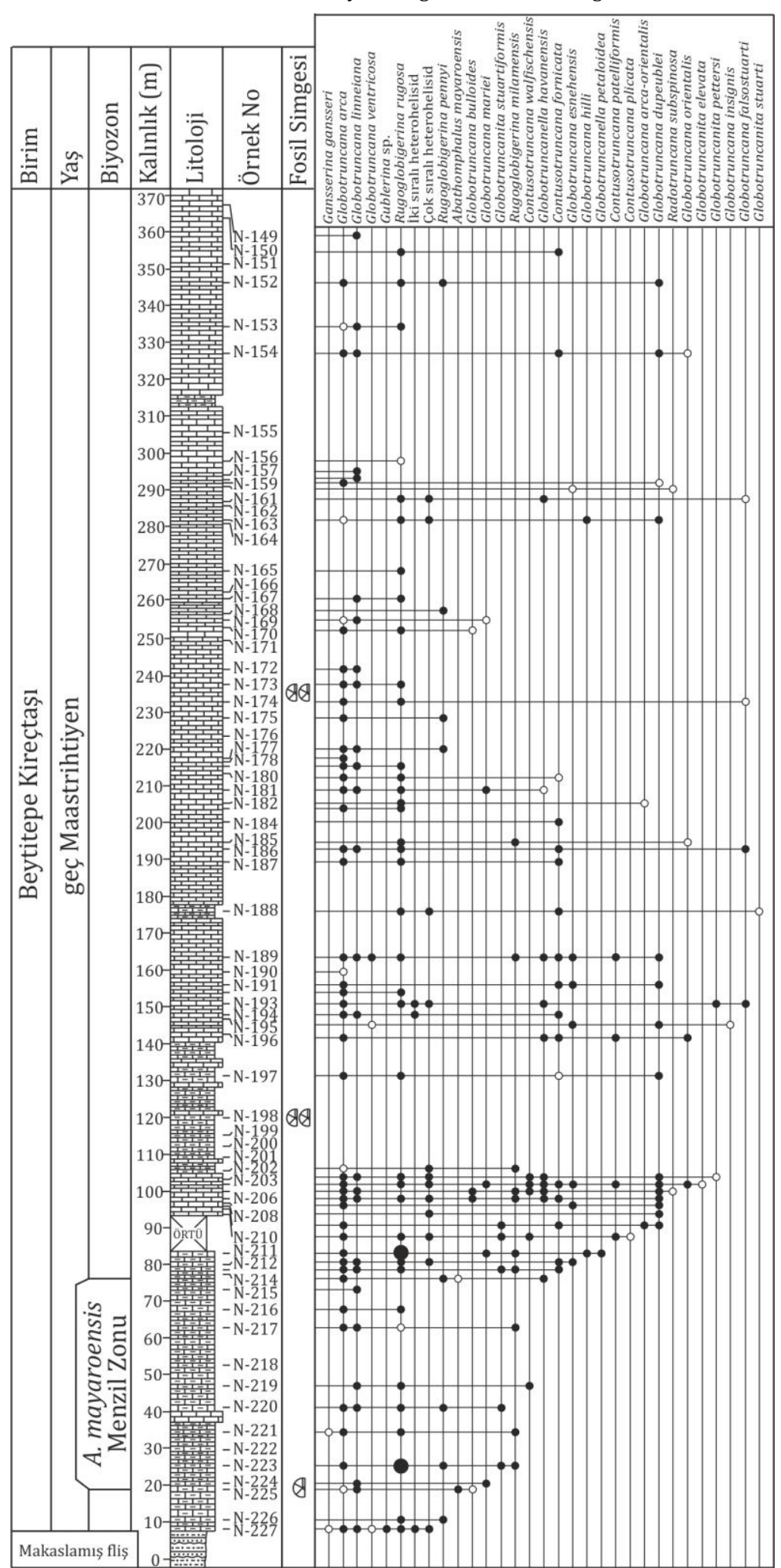

Şekil 10. Gökdere ÖSK-2'de planktonik foraminiferlerin stratigrafik dağılımı. 
$\mathrm{Bu}$ formların daha yaşlı düzeylerden taşındığına dair herhangi bir veri gözlenmez. Daha alt düzeylerde $A$. mayaronesis'in gözlenmesi Gt. elevata'nın geç Maastrihtiyen yaşlı bir istif içinde yer aldığını gösterir (Şekil 9,10,12). Bu veri, Gt. elevata'nın stratigrafik dağılımının tartıșılırken daha dikkatli olunması gerektiğini gösterir.

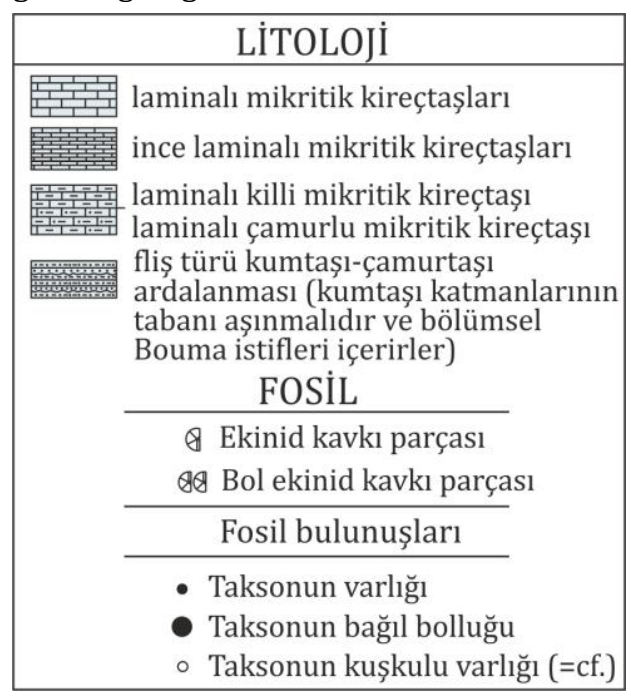

Şekil 11. Ölçülü stratigrafi kesitleri için litoloji ve fosil açıklamaları.

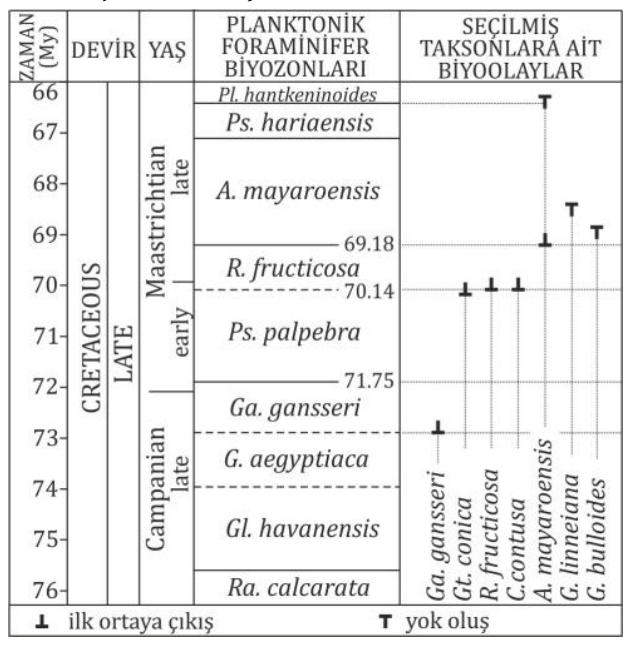

Şekil 12. Geç Kretase planktonik foraminifer biyozonları ve bu çalışmada tanımlanan bazı stratigrafik açıdan önemli taksonların biyoolayları (ilk ortaya çıkış ve yok oluş). Sayısal yaşlar, yaşlar, biyozonlar ve stratigrafik açıdan önemli taksonların ilk ve son görünüşleri [53] ve [54]'den alınmıștır.
$\mathrm{Bu}$ çalışma aynı zamanda, özellikle planktonik foraminifer bakımından fakir düzeylerin de olduğu bu tip kalın istiflerde sık örnek alımının istiflerin daha sağlıklı olarak yaşlandırılması açısından oldukça önemli olduğunu da göstermiştir. Nitekim, kesit hattının yaklașık $1 \mathrm{~km}$ KD'sinden [4] tarafından ölçülen kesitten elde edilen planktonik foraminiferlere göre istifin KampaniyenMaastrihtiyen yaşlı olduğu belirtilmiştir. Aynı istifin bu çalışma ile geç Maastrihtiyen yaşlı olduğu ortaya konulduğu düşünüldüğünde, bu durumun, örneklemenin seyrekliği nedeniyle, özellikle istifin alt bölümlerinde geç Maastrihtiyen formlarının saptanamamasından kaynaklandığını göstermektedir. Topluluklar içinde karenli globotruncanidlerin (K-seçilim) bolluğu bağıl olarak derin pelajik bir ortamı işaret eder. Çünkü, bu tip iri, kalın kavkıll, karmaşık morfotiplerin açı okyanuslarda deniz seviyesindeki yükselme dönemlerinde bollaştığı bilinmektedir $[21,49,50]$.

\section{Tartışma ve Sonuç}

$\mathrm{Bu}$ çalışma ile Gökdere istifinde yüzeyleyen Beytitepe Kireçtaşıı'nın planktonik foraminifer biyostratigrafisi ve istifin mikrofasiyes özellikleri ilk kez ortaya konulmuştur. 720 metrelik kalınlığa ulaşan kireçtaşı istifi, 360 metre kalınlığındaki düzeyin devrik senklinal oluşturacak şsekilde katlanmasıyla oluşmuştur. İstifi oluşturan laminalı mikritik kireçtaşlarında laminalanmayı da kesen yaygın yapraklanma düzlemleri gözlenmektedir. Planktonik foraminiferli vaketaşı mikrofasiyesinin baskın olduğu istifte karbonat çamurtaşı mikrofasiyesi de gözlenmektedir. Planktonik foraminiferlerin bolluğu örnekten örneğe değişmekle birlikte çoğunlukla ortaç bollukta gözlenirler. İstifin tabanından itibaren tüm istif boyunca seyrek de olsa A. mayaroensis'in gözlenmesi tüm kireçtaşı istifinin geç Maastrihtiyen yaşlı 

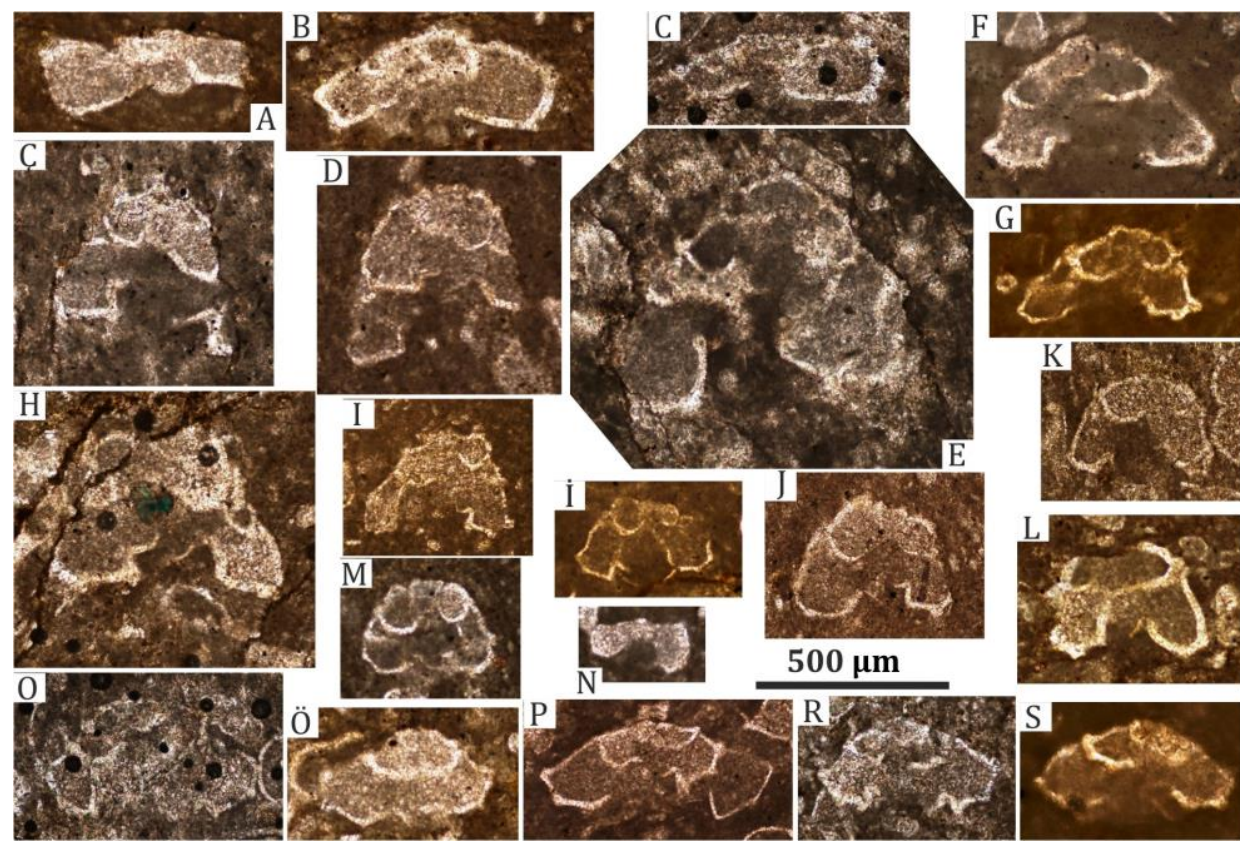

$500 \mu \mathrm{m}$
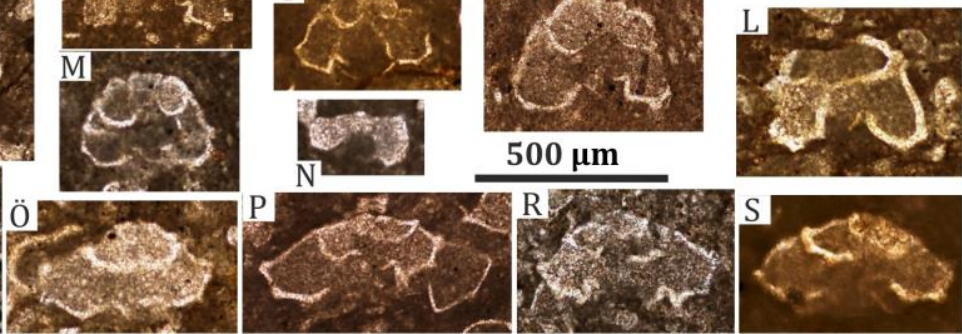

Şekil 13. Gökdere istifinde tanımlanan planktonik foraminiferlerin ince kesit görüntüleri. Tür adını takip eden rakam (N-90 gibi) örnek numarasına karşılık gelir. A) A. cf. mayaroensis, N-79, B,C) A. mayaroensis, N-90, N-92, C,,D) C. contusa, N-84, N-123, E) C. cf. contusa, N-82, F,G) C. fornicata, N-96, N-116, H) C. cf. patelliformis, N-90, I) C. patelliformis, N-102, İ) C. plummerae, N-130, J,K,L,M) C. walfischensis, N-123, N-91, N-90, N-91, N) Ga. cf. gansseri, N-95, 0,0̈,P,R) G. arca, N-92, N-92, N-120, N-88, S) G. arca-orientalis, N-104.

A. mayaroensis biyozonuna karşıllı geldiğini gösterir. Planktonik foraminifer topluluklarında gözlenen C. contusa, Gt. conica ve $R$. fructicosa diğer geç Maastrihtiyen yaşlı taksonlardır. Planktonik foraminifer toplulukları içinde özellikle istifin üst bölümlerinde $G$. linneiana'nın gözlenmesi istifin yaşının en geç Maastrihtiyen'e kadar uzanmadığını işaret eder. Böylece, [4] tarafindan Kampaniyen-Maastrihtiyen yașlı olduğu belirtilen istifin yașının geç Maastrihtiyen olduğu ve revize edilmesi gerektiği ortaya çıkmıştır. Elde edilen yaş verisi pelajik kireçtașlarının altında ve üstünde gözlenen fliş türü kırıntıllıların yaşının da geç Maastrihtiyen olduğunu belgelemesi açısından önemlidir. Planktonik foraminifer topluluklarında K-seçilim olarak nitelendirilen karmașık morfotiplerin baskınlığı, çökelimin açık denizde olduğunu gösterir. Gökdere istifi boyunca çeşitli düzeylerde Kampaniyen formu olarak bilinen Gt. elevata'nın gözlenmesi, taksonun geç Maastrihtiyen yaşlı tortullarda da bulunduğunu ve stratigrafik dağılımının küresel ölçekte gözden geçirilmesi gerektiğini gösterir.

\section{Teşekkür}

Arazi çalışmaları 102Y062 nolu Tübitak ve 2009.KB.FEN.064 nolu BAP projeleri tarafından desteklenmiştir. Arazi çalışmalarının bir bölümüne katılan Taner Korkmaz ve Ömer Ilgın'a teşekkür ederim. Makalenin ilk versiyonunu değerlendiren isimsiz iki hakeme değerli eleştiri ve katkıları nedeniyle ve dergi editörü Tolga Gönenç'e teşekkür ederim. 

Foraminifer Biyostratigrafisi ve Litostratigrafisi

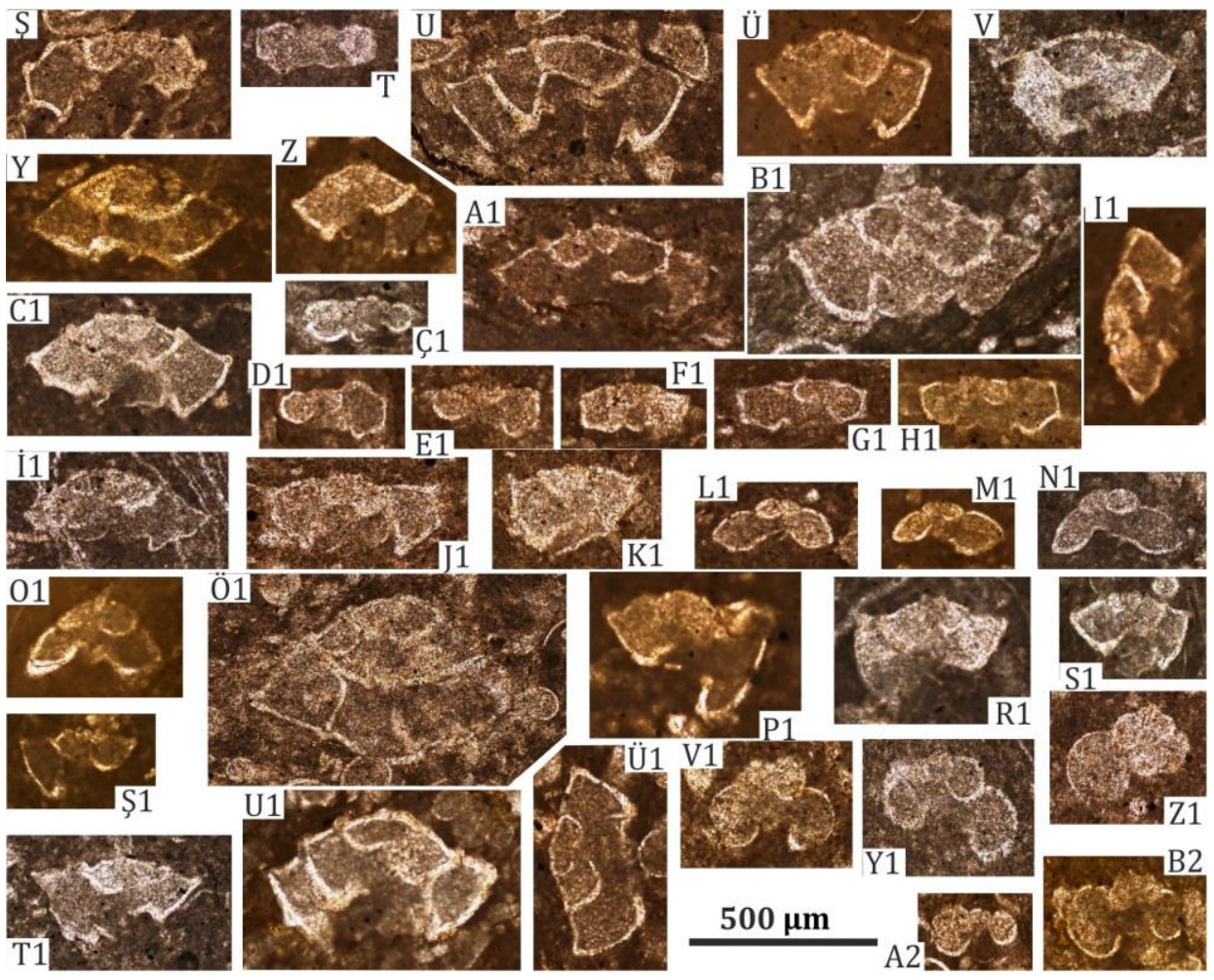

Şekil 13-Devam. Gökdere istifinde tanımlanan planktonik foraminiferlerin ince kesit görüntüleri. Tür adını takip eden rakam (N-90 gibi) örnek numarasına karşılık gelir.

Ș,T) G. bulloides, N-120, N-206, U,Ü,V) G. dupeublei, N-111, N-130, N-97, Y,Z) G. esnehensis, N121, N-191, A1,B1,C1) G. falsostuarti, N-117, N-94, N-193, Ç1,D1,E1) G. hilli, N-85, N-211, N119, F1,G1,H1) G. linneiana, N-102, N-91, N-212, I1) G. mariei, N-121, İ1) G. orientalis, N-127, J1,K1) G. ventricosa, N-112, N-189, L1,M1,N1) Gl. havanensis, N-102, N-121, N-206, 01) Gl. petaloidea, N-211, Ö1) Gt. cf. conica, N-111, P1) Gt. cf. elevata, N-104, R1) Gt. elevata, N-99, S1) Gt. insignis, N-96, \$̧1,T1) Gt. pettersi, N-101, N-80, U1) Gt. stuarti, N-92, Ü1) Gt. stuartiformis, N-113, V1,Y1,Z1) Ru. milamensis, N-202, N-213, N-189, A2,B2) Ru. rugosa, N$113, \mathrm{~N}-107$.

\section{Kaynakça}

[1] Okay, A.İ., Altıner, D. 2007. A condensed Mesozoic succession North of İmir: A fragment of the Anatolide-Tauride platform in the Bornova Flysch Zone, Turkish Journal of Earth Sciences, Cilt. 16, s. 1-23.

[2] Okay, A.İ., İşintek, İ., Altıner, D., Özkan-Altıner, S., Okay, N. 2012. An olistostrome-mélange belt formed along a suture: Bornova Flysch zone, western Turkey. Tectonophysics,
Cilt. 568-569, s. 282-295. DOI: 10.1016/j.tecto.2012.01.007

[3] Erdoğan, B. 1990a. Tectonic relations between İzmir-Ankara Zone and Karaburun Belt, Mineral Research and Exploration Institute (MTA) of Turkey Bulletin, Cilt. 110, s. 1-15.

[4] Erdoğan, B. 1990b. İzmir-Ankara Zonu'nun, İzmir ile Seferihisar arasındaki bölgede stratigrafik özellikleri ve tektonik evrimi, Türkiye Petrol Jeologları Derneği Bülteni, Cilt. 2, s. 1-20.

[5] Erdoğan, B., Altıner, D., Güngör, T., 
B.SARI / Beytitepe Kireçtaşı'nın (Bornova Fliş Zonu) Gökdere Alanında (İzmir, Batı Türkiye) Planktonik Foraminifer Biyostratigrafisi ve Litostratigrafisi

Özer, S. 1990. The stratigraphy of the Karaburun peninsula, Mineral Research and Exploration Institute (MTA) of Turkey Bulletin, Cilt. 111, s. 1-23.

[6] İşintek, İ., Masse, J.P., Altıner, D., Işın B. 2000. Age of a bauxite-bearing limestone block in the Bornova Wild Flysch Zone of the Taurides. International Earth Sciences Colloquium on the Aegean Region, 67.

[7] İşintek, İ., Altıner, D., Özkan-Altıner, S., Masse, J.P. 2006. Geology and the age of the bauxite-bearing limestone block in the Bornova Wildflysch Zone of the Taurides (İzmir, western Turkey). 59 $9^{\text {th }}$ Geological Congress of Turkey, Ankara, 225226.

[8] İşintek, İ., Altıner, D., Özkan-Altıner, S., Tekin, U. K. 2009a. New fossil data from a carbonate sequence of Middle Triassic to Early Malm age within the Bornova Flysch Zone (south of Soma, Manisa, western Turkey). 62 ${ }^{\text {nd }}$ Geological Congress of Turkey, Ankara, 690-691.

[9] İşintek, İ., Altıner, D., Özkan-Altıner, S. 2009b. Role of foraminifera in understanding the geology of Triassic-Cretaceous carbonate rocks in southwest of Kırkağaç (Manisa, Western Turkey). 62 $2^{\text {nd }}$ Geological Congress of Turkey, Ankara, 694695.

[10] Senowbari-Daryan, B., İşintek, İ. 2008. Izmirella cretacea nov. gen., nov. sp., an enigmatic bioconstructing alga from the Lower Cretaceous, NE of Bornovaİzmir/Turkey, Geologia Croatica, Cilt. 61, s. 273-295.

[11] Yağmurlu, F. 1980. Bornova (İzmir) güneyi filiş topluluklarının jeolojisi, Türkiye Jeoloji Kurumu Bülteni, Cilt. 23, s. 141-152.

[12] Özer, S., İrtem, 0. 1982. IşılklarAltındağ (Bornova-İzmir) alanı Üst Kretase kireçtaşlarının jeolojik konumu, stratigrafisi ve fasiyes özellikleri, Türkiye Jeoloji Kurumu Bülteni, Cilt. 25, s. 41-47.

[13] Sarı, B. 2013. Late Maastrichtianlate Palaeocene planktic foraminiferal biostratigraphy of the matrix of the Bornova Flysch Zone around Bornova (İzmir, western Anatolia, Turkey), Turkish Journal of Earth Sciences, Cilt. 22, s. 143171. DOI: $10.3906 /$ yer-1107-2

[14] Lirer, F. 2000. A new technique for retrieving calcareous microfossils from lithified lime deposits, Micropaleontology, Cilt. 46, s. 365369.

[15] Sarl, B. 2009. Planktonic foraminiferal biostratigraphy of the Coniacian-Maastrichtian sequences of the Bey Dağları Autochthon, western Taurides, Turkey: Thin section zonation, Cretaceous Research, Cilt. 30, s. 1103-1132. DOI: 10.1016/j.cretres.2009.03.007

[16] Sliter, W.V. 1989. Biostratigraphic zonation for Cretaceous planktonic foraminifers examined in thin section, Jornal of Foraminiferal Research, Cilt. 19, s. 1-19.

[17] Sarı, B. 2006a. Upper Cretaceous planktonic foraminiferal biostratigraphy of the Bey Dağları autochthon in the Korkuteli Area, Western Taurides, Turkey, Journal of Foraminiferal Research, Cilt. 36, s. 241-261.

[18] Robaszynski, F., Caron, M., Gonzales Donoso, J.M., Wonders, A.A.H. 1984. Atlas of Late Cretaceous Globotruncanids, Revue de Micropaleontologie, Cilt. 26, s. 145305.

[19] Caron, M. 1985. Cretaceous planktic foraminifera. ss 17-86. Bolli, H.M., Saunders, J.B., Perch-Nielsen, K. ed. Plankton Stratigraphy, Cambridge University Press. Cambridge, 86 p.

[20] Premoli Silva, I., Sliter, W.V. 1994. Cretaceous planktonic foraminiferal biostratigraphy and evolutionary 
B.SARI / Beytitepe Kireçtaşı'nın (Bornova Fliş Zonu) Gökdere Alanında (İzmir, Batı Türkiye) Planktonik Foraminifer Biyostratigrafisi ve Litostratigrafisi

trends from the Bottacione section, Gubbio, Italy, Palaeontographia Italica, Cilt. 82, s. 1-89.

[21] Robaszynski, F., Caron, M. 1995. Cretaceous planctonic foraminifera: comments on the EuropeMediterranean zonation, Bulletin de la Société Géologique de France, Cilt. 166, s. 681-692.

[22] Premoli Silva, I., Sliter, W.V. 1999. Cretaceous paleoceanography: Evidence from planktonic foraminiferal evolution. ss 301-328. Barrera, E., Johnson, C.C. ed. 1999. The Evolution of Cretaceous OceanClimatic System. Geological Society of America, Special Paper 332.

[23] Robaszynski, F., Gonzales Donoso, J.M., Linares, D., Amedro, F., Caron, M., Dupuis, C., Dhondt, A.V., Gartner, S. 2000. Le Crétacé supérieur de la région de Kalaat Senan, Tunisie centrale. Litho-biostratigraphie intégrée: zones d'ammonites, de foraminifères planctoniques et de nannofossiles du Turonien supérieur au Maastrichtien, Bulletin des Centres de Recherches Exploration-Production ElfAquitaine, Cilt. 22, s. 359-490.

[24] Premoli Silva, I., Verga, D. 2004. Practical manual of Cretaceous planktonic foraminifera. Verga, D., Rettori, R. ed. International School on planktonic foraminifera, $3^{\text {rd }}$ Course: Cretaceous. Universities of Perugia and Milan, Tiporafia Pontefelcino, Perugia (Italy), 283 s.

[25] Sarı, B. 2006b. Foraminifera-rudist biostratigraphy, Sr-C-Isotope stratigraphy and microfacies analysis of the Upper Cretaceous sequences of the Bey Dağları autochthon (western Taurides, Turkey). Dokuz Eylül Üniversitesi Fen Bilimleri Enstitüsü, Doktora Tezi, 436 s, İzmir.

[26] Sarı, B. 2017. Lithostratigraphy and planktonic foraminifera of the uppermost Cretaceous-Upper
Paleocene strata of the Tavas nappe of the Lycian nappes (SW Turkey), Geologia Croatica, Cilt. 70, (basimda).

[27] Robaszynski, F. 1998. Planktonic foraminifera-Upper Cretaceous, Chart of Cretaceous Biochronostratigraphy. de Graciansky, P.C., Hardenbol, J., Vail, P.R. ed. Mesozoic and Cenozoic sequence stratigraphy of European basins. Society for Sedimentary Geology (SEPM), Special Publication 60,782 s.

[28] Gradstein, F. M., Ogg, J. G., Schmitz, M. D., Ogg, G. M. (ed.) 2012. The geologic time scale 2012. Amsterdam, the Netherlands, Elsevier, $1144 \mathrm{~s}$.

[29] Embry, A. F., Klovan, J. E. 1971. A Late Devonian reef tract on northeastern Banks Island, Northwest Territories. Can. Petrol. Geology Bull. Cilt. 19, s. 730-781.

[30] Dunham, R. J. 1962. Classification of carbonate rocks according to depositional texture. Ham, W. E. ed. Classification of Carbonate Rocks. Am. Ass. Petrol. Geol. Mem. Cilt. 1, s. 108-121.

[31] Akartuna, M. 1962. İzmir-TorbalıSeferihisar-Urla bölgesinin jeolojik etüdü, İstanbul Üniversitesi Fen Fakültesi Monografisi, Cilt. 18, s. 2229.

[32] Verdier, J. 1963. Kemalpaşa Dağ etüdü (İzmir ili), Maden Tetkik ve Arama Dergisi, Cilt. 61, s. 23-40.

[33] Oğuz, M. 1966. Manisa dağının kuzey ve kuzeybatısının jeolojisi. Ege Üniversitesi Fen Fakültesi İlmi Raporlar Serisi, Cilt. 33, s. 6-7.

[34] Marengwa, B. S. 1968. Geologie des Gebietes Zwischen Ișılklar und Buca Östlich İzmir (Turkei). Vorgelegt der Matematich-Naturwissenchaftlichen Fakultat der Universitat Hamburg, $48 \mathrm{~s}$.

[35] Brinkmann, R. 1966. Geotektonische Gliederung von Westanatolien. 
B.SARI / Beytitepe Kireçtaşı'nın (Bornova Fliş Zonu) Gökdere Alanında (İzmir, Batı Türkiye) Planktonik Foraminifer Biyostratigrafisi ve Litostratigrafisi

Neues Jahrbuch Geologische Paleeontologische, Monatsch, Cilt. 10, s. 603-608.

[36] Brinkman, R. 1972. Mesozoic troughs and crustal structure in Anatolia, Geol. Soc. America Bulletin, Cilt. 83, s. 819-826.

[37] Brinkman, R. 1976. Geology of Turkey, enke, Stuttgart. $158 \mathrm{~s}$.

[38] Konuk, T. 1977. Bornova filişinin yaşı hakkında, Ege Üniversitesi Fen Fakültesi Dergisi, Seri B, Cilt. 1, s. 65-74.

[39] Akdeniz, N., Öztürk, Z., Konak, N., Çakır, M. H., Serdaroğlu, M., Armağan, F., Çatal, E. 1982. İzmirManisa dolaylarının stratigrafisi ve yapısal özellikleri. Türkiye Jeoloji Kongresi, Bildiri özleri, 49-50.

[40] Poisson, A., Şahinci, A. 1988. La série mésozoique de Kemalpaşa et le flysch paléocene d'İzmir auNordOuest du Menderes (Anatolie occidentale, Turquie). Un jalon du microcontinent taurique, Comptes rendus de l'Académie des sciences Paris, Cilt. 307, s. 1075-1080.

[41] Özer, S. 1989. Sur une faune d' Hippuritides des calcaires du Cretace superieur de la zone d' İzmir-Ankara (Anatolie occidentale). Interet paleontologique et stratigraphique, Revue de Paleobiologie, Cilt. 8, s. 335-343.

[42] Tansel, $\dot{\mathrm{I}}$. 1990. Balıklıova formasyonunun (Karaburun-İzmir) planktik foraminiferlere göre yaş konağı, Selçuk Üniversitesi Mühendislik-Mimarlık Fakültesi Dergisi, s. 41-50.

[43] Okay, A.İ., Siyako, M. 1993. The new position of the İzmir-Ankara NeoTehyan suture between İzmir and Balıkesir. Turgut, S. ed. Tectonic and Hydrocarbon Potential of Anatolia and Surrounding Regions. Proceedings of the Ozan Sungurlu Symposium, Ankara, s. 333-355.

[44] İşintek, İ., Altıner, D., Özkan-Altıner, S. 2007. Foraminiferal and algal biostratigraphy and paleogeographic implications of the Mesozoic carbonate bodies between İzmir and Soma (Manisa). TÜBİTAK Proje Sonuç Raporu, 213 s.

[45] Solak, C., Taslı, K., Sarı, B. 2015. Stratigraphy and depositional history of the Cretaceous carbonate successions in the Spil Mountain (Manisa, W Turkey), Cretaceous Research, Cilt. 53, s. 1-18. DOI: 10.1016/j.cretres.2014.10.008

[46] Bolli, H.M. 1957. The genera Praeglobotruncana, Rotalipora, Globotruncana and Abathomphalus in the Upper Cretaceous of Trinidad, B.W.I. In: Loeblich, A.R.Jr. and collaborators, ed. 1957 Studies in Foraminifera. United States National Museum Bulletin, Cilt. 215, s. 51-60.

[47] Coccioni, R., Premoli Silva, I. 2015. Revised Upper Albian-Maastrichtian planktonic foraminiferal biostratigraphy and magnetostratigraphy of the classical Tethyan Gubbio Section (Italy), Newsletter on Stratigraphy, Cilt. 48/1, s. 47-90. DOI: $10.1127 / \mathrm{nos} / 2015 / 0055$

[48] Premoli Silva, I., Bolli, H.M. 1973. Late Cretaceous to Eocene planktonic foraminifera and stratigraphy of Leg 15 Sites in the Caribbean Sea, Initial Reports of the Deep Sea Drilling Project, Cilt. 15, s. 499-547.

[49] Caron, M., Homewood, P. 1983. Evolution of early planktic foraminifers, Marine Micropaleontology, Cilt. 7, s. 453462.

[50] Abramovich, S., Yovel-Corem, S., Almogi-Labin, A., Benjamini, C. 2010. Global climate change and planktic foraminiferal response in the Maastrichtian, Paleoceanography, Cilt. 25, s. PA2201. DOI: 10.1029/2009PA001843

[51] Görür, N., Tüysüz, O. 2001. 
B.SARI / Beytitepe Kireçtaşı́nın (Bornova Fliş Zonu) Gökdere Alanında (İzmir, Batı Türkiye) Planktonik Foraminifer Biyostratigrafisi ve Litostratigrafisi

Cretaceous to Miocene

Palaeogeographic evolution of

Turkey: Implications for

hydrocarbon potential, Journal of

Petroleum Geology, Cilt. 24, s. 1-28.

[52] Erentöz, C. 1964. 1:500.000 ölçekli İzmir Paftası Jeoloji Haritası, Maden Tetkik ve Arama Enstitüsü (MTA) Yayınları.

[53] Ogg, J. G., Hinnov, L. A. 2012. Cretaceous. ss 793-854. Gradstein, F. M., Ogg, J. G., Schmitz, M. D., Ogg, G.M. ed. 2012. The Geologic Time Scale 2012, Volume 2. Amsterdam, the Netherlands, Elsevier, 1144 s. DOI: 10.1016/B978-0-444-594259.00001-9

[54] Anthonissen, D. E., Ogg, J. G. (derleyenler) 2012. Appendix 3: Cenozoic and Cretaceous biochronology of planktonic foraminifera and calcareous nannofossils. ss. 1083-1127. Gradstein, F. M., Ogg, J. G., Schmitz, M. D., Ogg, G.M., ed. 2012. The Geologic Time Scale 2012, Volume 2. Amsterdam, the Netherlands, Elsevier, 1144 s. DOI: 10.1016/B978-0-444-594259.00001-9 